\title{
Sobretudo, a esperança ${ }^{1}$
}

\author{
Cláudia Maria Fernandes Corrêa \\ Universidade de São Paulo (São Paulo, Brasil)
}

reces e súplicas ou os cânticos de desesperança (Lisboa: Instituto Piaget, 2005, 106 p., Colecção Poética e Razão Imaginante) assinala mais uma vez o envolvimento de Vera Duarte com as causas sociais. Caboverdiana do Mindelo, Ilha de São Vicente, desde muito jovem se dedicou a escrever. Em 1976 participou do concurso literário "Jogos Florais 1976" para comemorar o primeiro aniversário da independência, obtendo Menção Honrosa. Em 1981, obtém o $1^{\circ}$. lugar com uma coletânea de oito poemas dedicados à mulher em um concurso organizado pela Organização das Mulheres de Cabo Verde, a OMCV. Seguiu o caminho do Direito e se tornou a primeira mulher magistrada em Cabo Verde. Foi Presidente da Comissão Nacional para os Direitos Humanos e Cidadania em Cabo Verde até 2008. Em 1993 assumiu, como primeira mulher, a Comissão Africana do Direito dos Homens e dos Povos, e, pela sua atividade em prol dos Direitos Humanos, recebeu o prêmio Norte-Sul de Direitos Humanos de Lisboa do Centro Norte-Sul do Conselho da Europa. Foi Ministra da Educação e Ensino Superior de Cabo Verde de 2008 a 2010 e, também em 2010, foi condecorada com a Medalha de Primeira Classe da Ordem do Vulcão pelo Presidente da República de Cabo Verde, por sua relevância na área das Letras.

Sua obra de estreia, Amanbã Amadrugada, de 1993, foi seguida por $O$ arquipélago da paixão, em 2001, que recebeu o prêmio TCHICAYA U TAM' SI de poesia africana, e pelo romance $A$ candidata, de 2004, que recebeu o prêmio SONANGOL de literatura. Seu mais recente livro de poemas é Preces e súpli-

1. DUARTE, Vera. Preces e súplicas on Os cânticos da desesperança. Lisboa: Instituto Piaget, 2005, 106 p. (Poética e Razão Imaginante). 
cas ou os cânticos da desesperança, de 2005. Em 2007 publicou uma coletânea de ensaios na área dos Direitos Humanos intitulada Construindo a utopia: temas e conferências sobre Direitos Humanos.

Em Preces e súplicas ou os cânticos da desesperança, Vera Duarte se volta à memória da escravização e inicia a obra com um olhar ao passado distante:

Diz-se que ao longo de três séculos cerca de vinte milhões de escravos passaram pela Ilha de Gorée, no Senegal. Muitos não resistiram ao cativeiro. Esse livrinho de poemas é uma homenagem que presto a esta nossa ancestralidade (DUARTE, 2005, p. 8).

O sujeito poético de Preces e súplicas navega nas águas do passado para, a partir de lá, explicar a situação de pobreza, miséria, doença e fome não apenas da África, mas de todos aqueles países vítimas da tirania, da guerra, da dominação que, no mundo contemporâneo, metaforizam os sete pecados capitais, isto é, “as sete cabeças do nosso horror" (DUARTE, 2005, p. 70).

O sujeito poético de Preces e súplicas padece em comunhão com aqueles cujas vozes não têm eco e, em união com os "excluídos da terra" (DUARTE, 2005, p. 79), suplica por justiça contra esse "destino implacável” (DUARTE, 2005 , p. 84) que persiste. Por eles, o sujeito poético brada ferozmente, denunciando a condição abjeta e desumana a que muitos submetidos.

Oiçam-me ó vós

Que dominais o mundo

Tenho fome

Tenho sede

Tenho frio

Tenho ódio

[...]

Mas oiçam também

$\mathrm{O}$ imenso abandono

O sofrimento antigo e indizível

O implacável calvário

Que a cada minuto

Século a século 
Acto a acto

Se abate sobre mim

(DUARTE, 2005, p. 81; 82)

Para os oprimidos, a globalização é apenas a extensão do Imperialismo, com sua promessa de integração, encurtamento das distâncias, acesso aos bens de consumo; é uma ilusão para aqueles que não são parte do projeto da nação globalizada. Neste sentido, Preces e súplicas ou os cânticos da desesperança chega a nós clamando por justiça e equidade a todos os marginalizados, excluídos e esquecidos pela globalização: homens, mulheres, crianças, com um

salutar lembrete das relações "neocoloniais" remanescentes no interior da "nova" ordem mundial e da divisão de trabalho multinacional. Tal perspectiva permite a autenticação de histórias de exploração e o desenvolvimento de estratégias de resistência (BHABHA, 2005, p. 25-26).

Em Preces e súplicas, o sujeito poético alinha-se àqueles para quem a justiça é sonho, relembrando as atrocidades de épocas passadas e presentes: a escravização, o Tarrafal, antigo campo de concentração no interior da Ilha de Santiago, em Cabo Verde, e hoje Museu da Resistência; as crianças órfãs, vítimas de genocídios ocorridos no Congo, em Ruanda e em Moçambique; as lutas para a libertação dos países africanos dominados por Portugal, a violência contra as mulheres africanas e, também, contra aquelas de Sarajevo, do Kosovo e da Colômbia; ou seja, os "sofrimentos antigos e multiformes" que "mataram sonhos e esperanças / e destruíram as utopias” (DUARTE, 2005, p.76).

Esse sujeito poético convoca para a luta outros líderes que dedicaram suas vidas a um mundo mais fraterno, justo e livre da dominação de qualquer ordem: Nelson Mandela, líder sul-africano que lutou contra o apartheid, e o brasileiro Sérgio Vieira de Mello, diplomata morto em um atentado em Bagdá, em 2003, para uma "insurreição de palavras / geradora e fecundante / De um tempo novo e redimido" quando recusarão "a sorte / a morte / E todos os sacrilégios" (DUARTE, 2005, p. 104). Porém, o sujeito poético conclama, em particular, às mulheres para que sejam os agentes de transformação da África e do mundo nos novos tempos, pois elas 


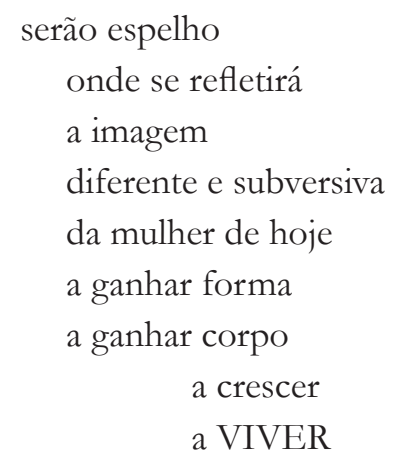

(DUARTE, 2005, p. 98)

Preces e súplicas ou os cânticos da desesperança está organizado em quatro partes. A primeira parte traz as súplicas com três poemas. A segunda parte da obra contém as preces que são sete ao todo, iniciada por um poema introdutório intitulado "Salvé poesia". É interessante notar que a primeira prece é dedicada a Eugénio de Andrade, poeta português falecido em 2005 cuja poética, assim como aquela de Vera Duarte, dá suma importância à palavra. A segunda prece é dedicada ao Congresso de Assilah; a terceira é uma homenagem a Adama Dieng, senegalês, Secretário-Geral Adjunto das Nações Unidas e escrivão do Tribunal Criminal Internacional para Ruanda. A quarta prece é dedicada aos excluídos da terra; a quinta prece é uma homenagem à memória de Sérgio Vieira de Mello; a sexta prece é dirigida às crianças africanas e a última prece é dedicada a Nelson Mandela.

A terceira parte, os "Poemas do antigamente / E de hoje...ainda!", é composta por seis poemas dedicados às mulheres. $\mathrm{O}$ sujeito poético fala às mulheres, mostrando-lhes sua condição que foi reduzida a "miséria/varizes/filhos" (DUARTE, 2005, p. 95) e, com seu grito, o sujeito poético espera acordá-las para essa realidade a elas imposta.

Nesse sentido, a poética de Vera Duarte em Preces e Súplicas enfatiza as experiência[s] de mulher, de exaltação dos sentidos [...] alternadas com extremos de sofrimento, desencanto, solidão e dolorosa alteridade, que não se esquece das guerras, das utopias, das revoluções de homens e mulheres, de seu Povo, de todos os povos do mundo (GOMES, 2008, p. 243).

A consciência da opressão e degradação não é o bastante. É preciso reagir contra ela e transformar a sociedade. O sujeito poético de Preces e súplicas pro- 
fetiza que, com esta transformação, será possível anunciar a Boa Nova: após a revolução, a vida tornar-se-á plena e abundante.

A quarta e última parte de Preces e súplicas é o "Cântico final e redentor", que contém dois poemas e um posfácio. Nestes poemas, o sujeito poético recupera a palavra ora perdida porque "sem a palavra / a ilha não existe" (DUARTE, 2005, p. 102). Sem a palavra, tudo é vazio, tudo é silêncio, tudo é dor. A palavra é veículo criador e revolucionário da poeta na construção de sua revolução, porque "Poema é entrega e abandono / E luta dos homens pela vida" (DUAR'TE, 2005, p. 103).

O último poema, "Poema somente", descortina um futuro claro e promissor após a transformação. O sujeito poético une-se a toda humanidade para celebrar o novo tempo que nasceu após o "holocausto redentor" (DUARTE, 2005, p. 75) quando haverá justiça, os direitos serão respeitados, não haverá crianças, mulheres e homens massacrados ou violados. Ocorrerá, então, a celebração da Páscoa, a passagem das trevas da morte e das dores à plenitude da vida, da qual participarão todos aqueles que lutaram pela justiça, ilustres e anônimos, salmodiando e elevando suas vozes não mais em Preces e súplicas, mas cantando a renovada e vivificada Esperança.

\section{Referências Bibliográficas}

BHABHA, Homi K. O local da Cultura. Tradução de Myriam Ávila, Eliana Lourenço de Lima Reis e Gláucia Renate Gonçalves. $3^{a}$. reimpressão. Belo Horizonte: Editora UFMG, 2005.

DUARTE, Vera. Preces e súplicas ou os cânticos da desesperança. Lisboa: Instituto Piaget, 2005, 106 p. (Colecção Poética e Razão Imaginante).

GOMES, Simone Caputo. Preces e súplicas ou os cânticos da desesperança, de Vera Duarte. In: . Cabo Verde: literatura em chão de cultura. Cotia (SP), Praia (Cabo Verde): Ateliê Editorial, Instituto da Biblioteca Nacional e do Livro, 2008, p.259-263.

Recebido em 08 de maio e aprovado em 01 de junho de 2011. 